\title{
A new methodology in generating Digital Plants in AVEVA PDMS from Navisworks® model
}

\author{
Reyhaneh Nasirifar $^{a^{*}}$, Shahram Shafeghati ${ }^{\mathrm{a}}$ and Iman Valipour ${ }^{\mathrm{a}}$
}

${ }^{a}$ Department of Progress Engineering, Iran University of Science and Technology, Tehran, Iran

\begin{tabular}{l}
\hline C H R O N I C L E \\
\hline Article history: \\
Received: May 82019 \\
Received in revised format: June \\
22019 \\
Accepted: June 92019 \\
Available online: \\
June 10 2019 \\
\hline Keywords: \\
AVEVA PDMS \\
Navisworks ${ }^{\circledR}$ \\
Abadan Oil Refinery \\
PML \\
.net code \\
3D model
\end{tabular}
A B S T R A C T

\begin{abstract}
In the past, due to the use of two-dimensional design, the probability of error in large projects increased. Over time, the need for a digital 3D model has increased in the lifetime of refineries, petrochemicals and power plants. Today, the editable digital 3D model is the basic needs of industrial plants. The Abadan Oil Refinery Co., due to its need for inspections and possible changes in the refinery, has also needed an editable 3D Digital Plant during the past few years. In this paper, with the development of a new methodology, the non-editable Navisworks ${ }^{\circledR}$ model of phase 1 and 3 of Abadan Oil Refinery was transformed into an editable Digital 3D model in AVEVA PDMS. In this methodology, the PDMS programming language called Programming Macro Language (PML) as well as .net code was used. Finally, using the Navisworks ${ }^{\circledR}$ model, these two phases, which consisted of 38 Areas, 2185 equipment, 17966 pipes, 7046 instruments, and 2617 structures were converted into an editable PDMS model for nine months.
\end{abstract}

\section{Introduction}

Plant design management system (PDMS) and its related application provide a powerful suit of facilities to create analysis documentation of a real-life plant in three dimensional representation in a logically interconnected system. In the eighteenth century after the industrial revolution, the rapid growth of the industry and the subsequent development of engineering took place. First, a foundation for designing industrial facilities and standards was created. Meanwhile, engineered support tools appeared. Then, with the help of the computer, the Computer Aided Drawing (CAD) toolbar seemed to support the design process. Most of the design works were carried out in a $2 \mathrm{D}$ environment using Computer Aided Drawing (CAD) Software packages (e.g., Autodesk AutoCAD®, Bently Microstation ${ }^{\circledR}$, etc.), that is, the drawings were created in the $2 \mathrm{D}$ plant. At the moment, tools for supporting designers are compatible with the new design philosophies. Before the IT revolution, the projects were archived as a set of written or printed documents on paper. It becomes clear that using traditional 2D design methods for large projects is extremely difficult to ensure the quality of working documentation. More and more customers begin to include in their requirements an inteligent three-dimensional (3D) model of the designed objects and all related information, the most advanced operators describe in detail, the attribute component of the elements and strictly * Corresponding author.

E-mail address: rnasirifar@gmail.com (R. Nasirifar) 
regulated the structure of the project. To meet the real work demands of design review, a 3D design review system is developed and the key technologies such as information organization model and multi-resolution rendering approach is proposed. The information organization model can organize all information from different CAD systems with a unified structure, and optimize the information query speed. Based on programmable graphics, the multi-resolution rendering approach can improve rendering efficiency in less preprocessing time, without using extra hard-disk space. 3D design review system can work on a general PC to review a large quantity of design information from different subjects, and ensure real-time interaction at the same time (Zhou et al., 2016).

\section{Literature Review}

Information revolution has changed business and society, and industries use new and advanced software tools to work effectively. New design philosophies focus on the project as a database, including the design and design of the 3D factory design. Objects in this database are presented simultaneously in designs, 3D models and other documents. The philosophy behind these ideas is the BIM (Building Information Modeling). However, not only design methods change, but also change their operation paradigms and behavior (Płocharczyk, 2018). A study conducted in 2017 in the Middle East region, identified the most common Building Information Modeling (BIM) tool used in this region; this was Revit followed by AutoCAD. Even though BIM implementation in the Middle East has increased in the past 5 years, site professionals still use 2D drawings for erection and placement. Other software and Building Information Modeling (BIM) technologies such as Navisworks ${ }^{\circledR}$ were identified to be used essentially for construction schedule simulation, while Solibri, StaadPro, Civil 3D, and Robot structure were scarily used (Gerges et al., 2017). AVEVA has released an interface for its known AVEVA PDMS system for bipolar transfer control using a protocol for data exchange. This makes the plant designer produce a solid exact model of the equipment items created with its CAD 3D MCAD system. Using the AVEVA mechanical equipment interface, the designer can transform imported information into a 3D friendly design with the definition of nozzles and electrical connection points. Such design exchanges can also increase the efficiency of business in organizations where the relationship exists between the Client /Customer and the Supplier (McPhater, 2010). Customers have the opportunity to receive an additional product, a 3D model, which can be used at subsequent stages of the life cycle of an object as a digital asset and as a basis for building various information systems. In some cases, a company that designs industrial plants gives employer a non-editable three-dimensional model in Navisworks ${ }^{\circledR}$ format. Navisworks ${ }^{\circledR}$ is widely used in the construction industry to complete $3 \mathrm{D}$ design packages. This software allows users to open and combine 3D models, moving in real time. But non-editable file will be used to view the entire plants and provide some useful information during the design and construction phase of the project. Note that Clients/Owners need editable 3D models in the lifetime of petrochemical plants during the plant life cycle.

AVEVA PDMS (Plant Design Management Systems) in the field of integrated design and engineering applications, is definitely a global leader in the design and design of processing tools and life cycle management tools. For several companies in the United Kingdom, designing skills in accordance with developing technologies in the design process of the process pay great attention. This includes basic engineering skills in the design and operations of the company. This has led to continued learning opportunities for engineers and design managers. (Okey et al., 2008). Modern computer technology is used to update the process of traditional handheld $3 \mathrm{D}$ models. The system is checked, reviewed, and directed by rules, and includes two modes of operation: intelligent mode can be used by the designer to check the 3D model in real time, and the normal mode can be used to check the 3D model in the check-up process. The Software codes are written by AVEVA Macro Language Programming (PML) and Microsoft.Net C \# Framework. This not only makes the standardized and automated check process, but also makes the results more reliable (Wu., 2018).

Reasons for editable three-dimensional models requirement are mentioned as below: 
1- Need to change the model in the future based on plant modification / revamping,

2- Need to export updated Material Take off,

3- Need to export updated plant drawings (e.g., piping isometric drawings, plant arrangements, etc.),

4- Need to use updated drawings in other disciplines (e.g., operation, inspection disciplines, etc.).

Taking into account all the above factors and analyzing the various CAD systems, AVEVA Plant Design Management System (PDMS) platform is selected for the building of 3D model from Navisworks ${ }^{\circledR}$. The design of the manufacturer's equipment depends on a wide range of different determinants. For example, the normal diameter of the column, the wall thickness, and the output gap and the stress calculations for supporting beams are done during the design procedure. In addition to spatial and geometric information, all components, process data, plant, and planning data are in the unit modular data model. For example, material selection, operating conditions, tube class information, internal type and factory site information are included in the model. After importing the Modular Process Unit model into the CAD 3D environment, all this information is available for further use and can be imported directly into the AVEVA E3D / PDMS software (Filinger et al., 2017). Also electrical and instrument Cable design work involves multi-system data processing, though without a data integration platform based on $3 \mathrm{D}$ visualization this can be reduced human working. A cable design system is built to display the design data and cable data in a unified 3D plant model, which realizes the visualization and integration of multi-system information, and improves reliability and efficiency of the design work. This method can be applied to a variety of design systems and industries, and has a good scalability (Ying \& Xiao, 2017). Quantity take-off based on Building Information Modeling (BIM) is applied in industrial construction projects. However, there are limitation for BIM technology, due to the lack of data exchange standards, platform compatibilities and the availability of useable BIM models. An alternative method is to improve the efficiency of quantity take-off by automatically generating geometry information of construction components based on 3D viewing models. The 3D viewing model is the digital graphic representation of the object, and it has broadly compatible formats (Han, 2017).

PDMS is also a comprehensive modeling system that creates 3D designs and deliverables and features of the management model, clash management, visual inspection, automated routing and construction results. In addition, from its database, it manages engineering information such as frontend data, P \& ID, 3D model, project control, and material management bases. This software utilizes international standards and Client standards for encoding and tag numbering of equipment, ensuring that this product can be used in industries such as marine, oil industries and power plants (Goldberg, 2007).

The main characteristics of this product:

- Enable to handle super large projects due to it's database capabilities;

- Compliance with the needs of the design institute;

- The convenience of use;

- Methodical and technical support;

- ISO 15926 compliance;

- Integrated approach - the system covers all project disciplines;

- The minimum number of restrictions on the volume of designed objects (handling of large projects);

- It can be a basic foundation of inspection project;

- It can be a basic foundation of the as-built model;

- Very good customization capabilities;

Abadan Oil Refinery Co (AORC) is one of the oldest and biggest refineries in Iran. Most of the workers in this refinery are using 2D models, isometric drawing, hand-made 2D drawings, etc. Using 
2D drawings and visiting the site for all changes and all activities were time-consuming. Therefore, refinery managers decided to update their methodology and change existing traditional data management system to a new one by making an editable, live, and integrated data model (Digital Plant) of the whole refinery. Using 3D graphics simulation, we are able to process simulated models using complex environment distribution calculations. The flexible interface of the evolved interface between the simulator samples gives the system the convenience of combining other simulation tools. The integration of various software components extends the use of production simulation (Freund \& Pensky, 2003). Simulation models can potentially be used to provide support for other tasks, such as operational planning and service and maintenance. This requires that the simulation models can be fed with historic data as well as with snapshot data. Furthermore, the models must be able to communicate with other business software. Due to the various features and goals of 2D and $3 \mathrm{D}$ CAD tools, this type of data cannot be fully interpreted by other tools after importation. For example, the "functional" information exchange between P \& ID systems and 3D CAD can be mentioned. In P \& IDs, the information content of control structures is superior to the three-dimensional model. For example, due to the lack of graphical and functional display of signal lines, the data transferred from CAD 2D tools cannot be fully utilized in 3D CAD tools. In addition, some of the instrumentation information cannot be interpreted by the target system. In the case of 2D, graphical symbols, for example, are represented by lines, curves, and points. Data for graphic representation 2D icons cannot be used in all 3D profiles and can be seen from the other side (Fillinger et al., 2017). Simulated models can be used for operational planning and maintenance support. Advantages include better possibilities for confirming production plans and the ability to monitor and maintain machinery from remote locations. In addition, updated and constantly updated models are a good tool for studying the effect, for example, introducing a newly planned product in existing production systems. (Devin et al., 2004).

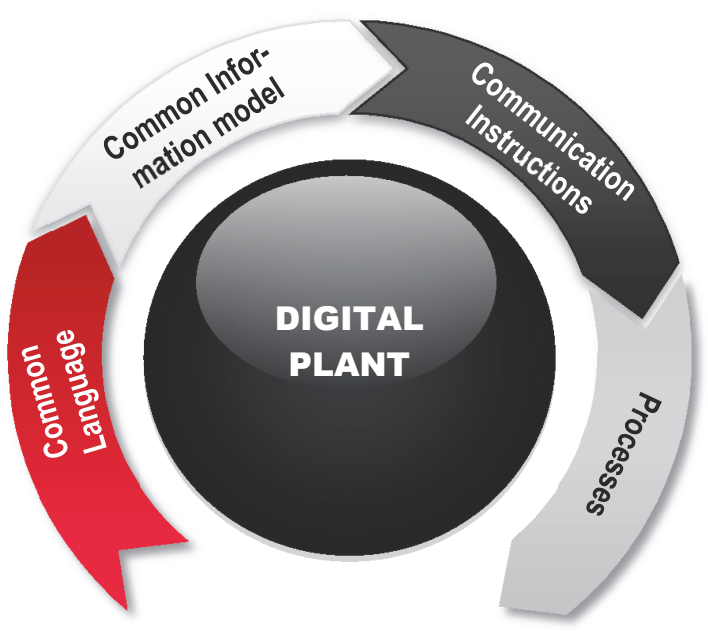

Fig. 1. Digital Plant block

This system has common data language, model and instructions to complete any type of process workflow. 3D digital development (3D) is a new way of getting real factory information. A digital plant colony modeling can operate on the basis of 3D digitization and is implemented by a group of corn. First, the spatial data of the corn colony is collected by a digitizer and the data is organized by the relevant files. In addition, the unique $3 \mathrm{D}$ model is based on the main points. Therefore, the corn colony model is expressed by several key parameters. The results of the experiment indicate that the modeling method is effective for plant colony modeling (Xiao et al., 2011). All engineering and As-built engineering information is mission critical to reliable operations. Due to unavoidable modifications throughout a plant life, the quality and availability of as-built information rub over time. Combining engineering data with site survey use to build intelligent databases, 3D models and $2 \mathrm{D}$ engineering deliverables. Having a digital asset throughout the plant life cycle reduces the 
need of site visits for data gathering, minimizes the hazard occurs in the plant and provides high quality input data during any decision making. The digital plant asset can be used for true decision making and ensure data is centralized, accurate, change-controlled and accessible in the processes it supports (Elnaggar et al., 2015). As mentioned above no editable 3D model is exists, and AORC has only some Navisworks ${ }^{\circledR}$ 3D models and a large number of documents in Portable Document Format (PDF) for old parts of refinery. Therefore, for the first step, AORC decided to make Digital Plant with converting of existing Navisworks ${ }^{\circledR}$ 3D models to the PDMS model.

In recent years, 3D data mining and plant regeneration have been developed as a hot topic for scientific research. However, the morphological structure of the plants is very complex and describes the details. The data collection approach is diverse for different parts of the plant. The 3D data collection tool is used to obtain the morphometric of each target. The smallest particle needs a high-resolution scanner to get morphological details, while the plant sink is the hardest part to process and model the cloud-dot. Data and models rebuilt to the digital plant and popular science education program (Wen et al., 2017). AVEVA also has another collection called Everything 3D (E3D). The main task of its design is to support the accurate display of the plant during the design and construction phase. The software recognizes where $3 \mathrm{D}$ data points represent a pipe or a beam, and offers a selection of items possibly related to the catalog. The user then made the appropriate choice, for example, by choosing the correct pipe profile, and the system for creating a 3D intelligent entity in the design system, built on the data. This article is focused on phase 3 and phase 1 of Abadan Oil Refinery to convert Navisworks ${ }^{\circledR} 3 \mathrm{D}$ models of these phases to PDMS 3D model and also preparing all fundamentals to use this model as core of Digital Plant without any point cloud process modeling. This refinery produces these products:

1) Liquid gas,

2) Gasoline engine,

3) Kerosene,
4) Gas oil,

5) Jet fuel,

6) Fuel oil,
7) Types of base oil lubricants,

8) Types of bitumen,

9) Types of petroleum solvents,
10) Sulfur,

11) Nafta (Bandar-Emam Petrochemical feed),

12) Gas (Abadan Petrochemical Feed)

\section{Phase 1 introduction}

This phase contains:

- 9 Areas

- 455 Equipment

- 4,746 Pipes

- 570 Instrument

- 1,300 Structures

Phase 3 introduction

This phase of AORC includes a complex of crackers and alkalinity, the butane isomerization and renovation of the acid unit, which aims to produce more gasoline and reduce fuel oil were done. The gasoline output will increase by 6 million liters per day after this project completed. This phase contains:
- 29 Areas
- 1,730 Equipment
- $\quad 13,220$ Pipes
- $\quad 6,476$ Instrument
- $\quad 1,317$ Structures 


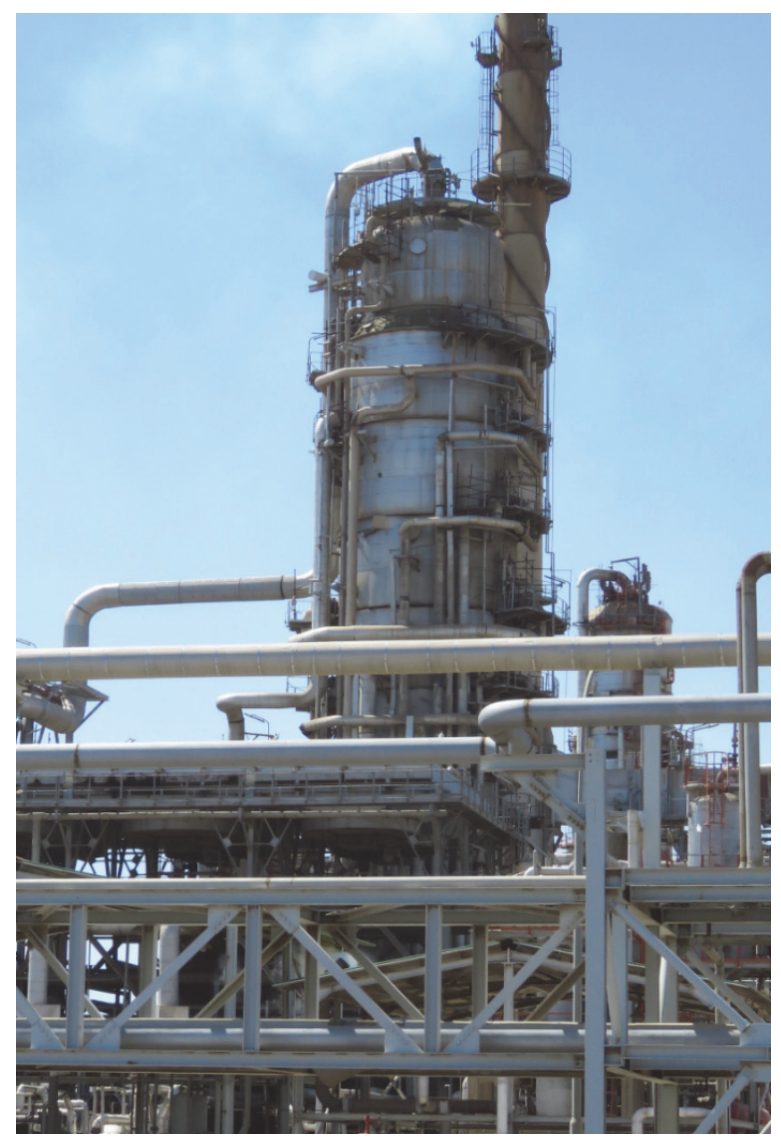

Fig. 2. Phase 3 Abadan Oil Refinery Co

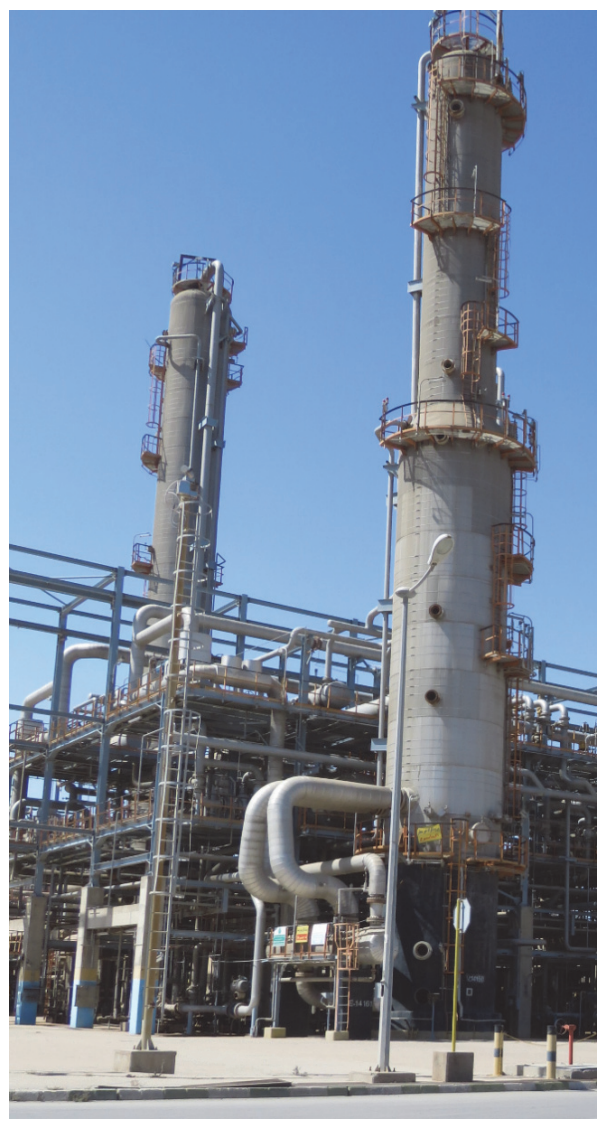

Fig. 3. Abadan Oil Refinery Co Phase 3

\section{Methodology}

The 3D-model will be created in PDMS and contains all items to be found in the Navisworks ${ }^{\circledR}$ 3D model including all equipment, piping, steel structures, pipe racks, concrete parts, foundations, bottom plates, retaining walls, channels, pits, platforms, stairs, ladders, railings, electrical tranches, instrumentation items, etc. with correct representation (as per Navisworks ${ }^{\circledR}$ input file) and have be transferred to PDMS model in semi-automated process. Before the start of conversion, all PDMS administration activities have be done in collaboration with Owner/Client team (as main Digital Plant user). Then the method of doing the conversion is divided into two steps of equipment / structure / foundations and piping.

At first, the methodology of converting equipment of Navisworks ${ }^{\circledR} 3 \mathrm{D}$ model to the PDMS 3D model is discussed. All geometry information of equipment in Navisworks ${ }^{\circledR}$ 3D model have been extracted by using a developed .net programming language in Navisworks ${ }^{\circledR}$ and for each equipment, Programmable Macro Language (PML) have be generated. The built in PML language in PDMS, allows the user to create tools for reducing designer work. Customizing the software through PML will risk that the modified macros are not compatible with next software versions. PML is an object-oriented language (Sandberg, 2017). The PML file includes all information and data that is required to create the equipment in PDMS environment including geometry information, nozzle specification and hierarchy data. Then the PML file has been imported to PDMS environment and equipment have been generated in correct position and hierarchy. The same process has been used for transferring the other parts of the plant (excluding pipes) to PDMS environment. It is possible to add specific functionality in the software with use of the programming macro language (PML). The PML allows access to the whole data and provides an interface to third-party programming languages. For example, with use of the PML it is possible to create a tool for exchanging the 
process stream data with chemical process simulators, like ChemCad, or to incorporate such safety analysis (Mitkowski\& Bal, 2015).

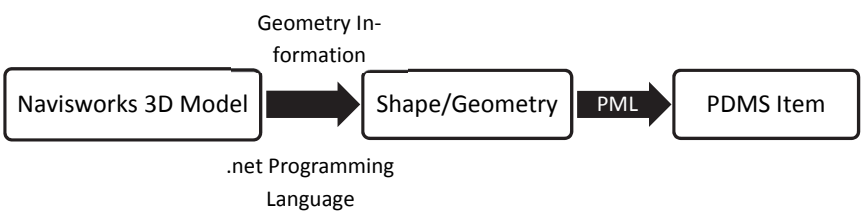

Fig. 4. Equipment / structure / foundations Navisworks ${ }^{\circledR} 3 \mathrm{D}$ model conversion flowchart

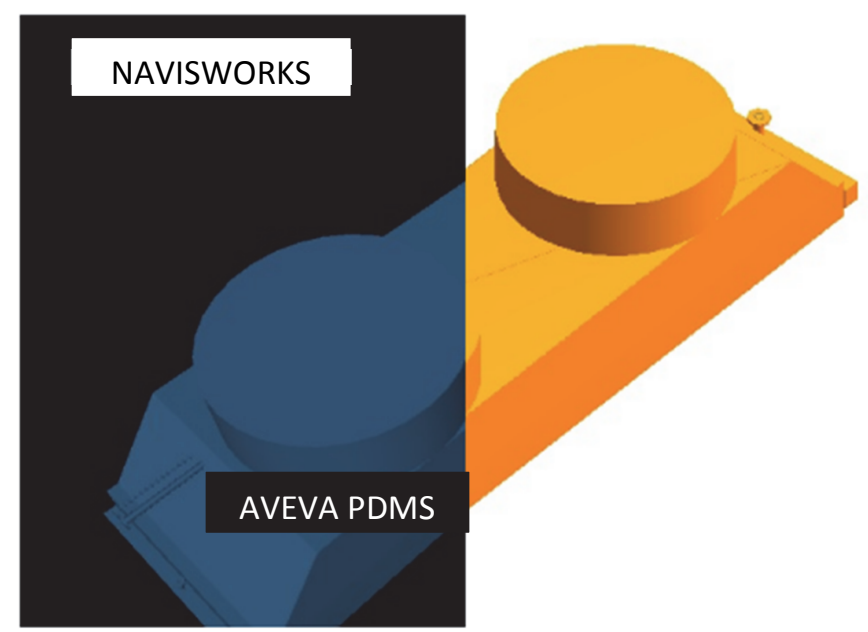

Fig. 5. Navisworks vs. PDMS Equipment's 3D Model

At the second step, piping parts of Navisworks ${ }^{\circledR} 3 \mathrm{D}$ model have been converted to 3D PDMS model. This items in Navisworks ${ }^{\circledR}$ 3D model has three basic information including geometry, hierarchy, and catalogue. Geometry and hierarchy are converted by developed net programming language code respectively to $3 \mathrm{D}$ shape and hierarchy list. Pipes route is also extracted from the Navisworks ${ }^{\circledR} 3$ D model. Catalogue part creates in PDMS environment by using Piping Material Specification (PMS) document that includes pipe classes, components definition, material definition, etc. PMS is used because of lack of this information in Navisworks ${ }^{\circledR}$ 3D model. Then all extracted parts are converted to PDMS 3D model by generating the PML files that contains all required data and their references to PDMS catalogue and piping have been fully modeled in PDMS DESIGN module. However, the representation of valves, filters, control valves, inline instrumentation, and other items is somewhere simplified as new generated PDMS catalogue if it is required. These converted models are checked, and if there was a contradiction between the PDMS 3D model and Navisworks ${ }^{\circledR}$ 3D model and other documents, piping components were reselected, and correct components were replaced.

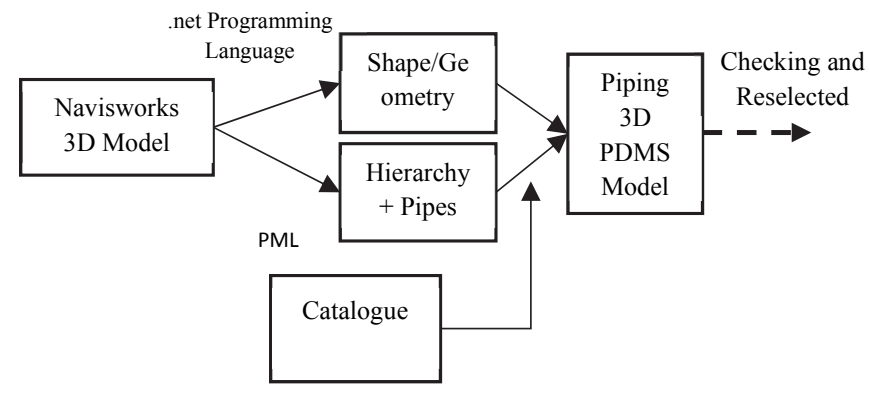

Fig. 6. Simple Flowchart of Piping Navisworks(R) 3D model conversion 
This semi-automated process covert all plant sections from Navisworks ${ }^{\circledR}$ 3D model to PDMS. The generated model will be fully checked by professional PDMS designers and random check with Navisworks ${ }^{\circledR}$ 3D model for special parts and will be ready to be the core of the Digital Plant.

\section{Result}

The PDMS 3D model of Phase 1 and Phase 3 (with parts mentioned above) have been generated with the semi-automated process in just nine months.

At first step following outputs have been generated:

1- An editable 3D model in PDMS environment with all benefits.

2- More than 103,000 sheets of piping isometric drawings including all required data for pipe fabrication, fully dimensioned pipe route, bill of material, pipe process data, etc.

3- Ready to extract piping plan, sections.

In the second step, this model has been used for data management of a large amount of data that have been gathered from the inspection team to feed in Risk Based Inspection (RBI) software.

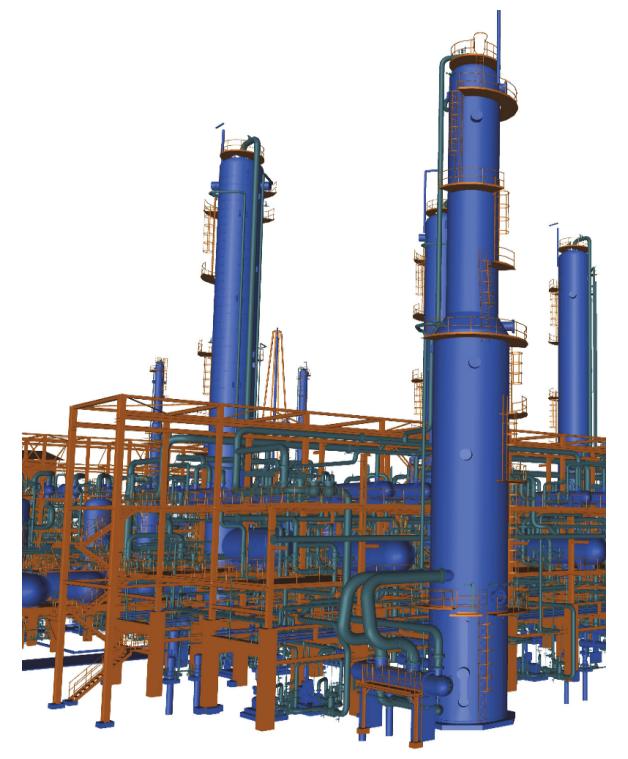

Fig. 7. Abadan Oil Refinery Co Phase 3 (3D Model)

\section{Conclusion}

Nowadays the importance of digital 3D model is not overlooked by anyone. AVEVA PDMS software creates a condition to make a digital 3D model with lots of benefits.

The PDMS software was used to provide a digital 3D model of Abadan Refinery. The benefits of the PDMS-based approach include:

1. High-speed conversion of the model

2. The structure of the PDMS Database (Dabacon) leads to more flexibility and high power in managing large volumes of information.

3. Easy to get output from PDMS software

4. Due to the programming capabilities of PDMS software, this software shows a high degree of flexibility in various activities. 
The developed code for converting models based on PDMS has had an error below $1 \%$. This error is also due to the definition of specific components that relate to the catalogue's work of the program. Therefore, this developed method can be used in all similar projects. Due to the capabilities described above, the Navisworks ${ }^{\circledR}$ model of phase 1 and 3 of AORC, which includes 38 Areas, 2185 equipment, 17966 pipe, 7046 instrument, and 2617 structures, converted to PDMS model in just nine months.

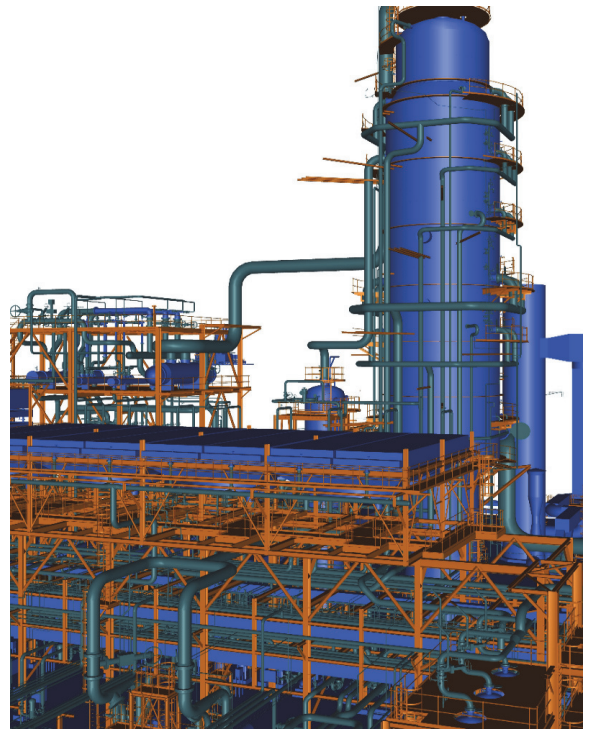

Fig. 8. Abadan Oil Refinery Co Phase 3 (3D Model)

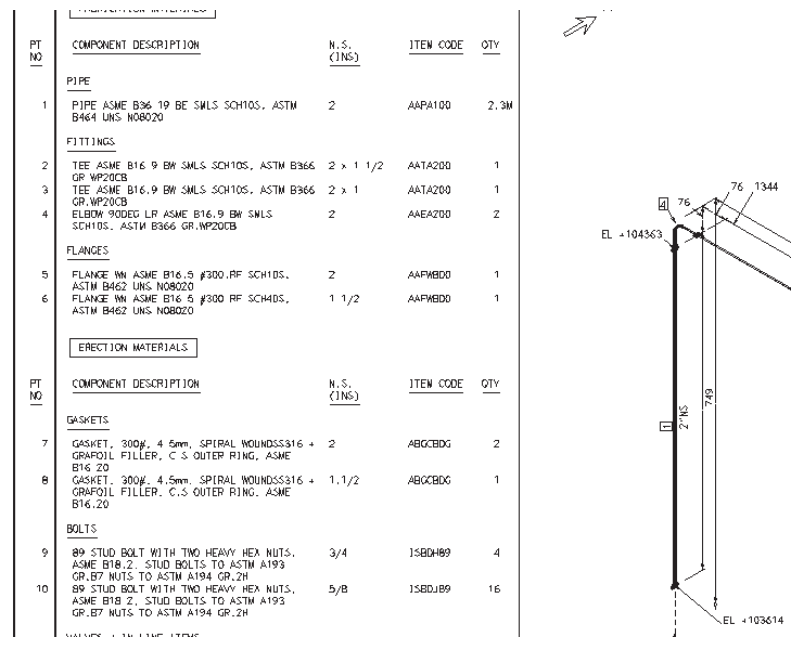

Fig. 9. Sample Piping Isometric Drawing (Isometric)

\begin{tabular}{|c|c|c|c|c|c|}
\hline Type & Bore1 & Bore2 & Detail & Material & Quantity \\
\hline CAP & $8^{\prime \prime}$ & $8^{\prime \prime}$ & CAP ASME B16.9 BW SMLS STD, & ASTM A234 GR.WPB & . \\
\hline CAP & $1 / 2 "$ & $1 / 2^{\prime \prime}$ & CAP ASME B16.11 \#3000, & ASTM A105 & 3 \\
\hline ELBO & $4 "$ & $4 "$ & ELBOW 90DEG LR ASME B16.9 BW SMLS STD, & & 34 \\
\hline ELBO & $6^{\prime \prime}$ & $6^{\prime \prime}$ & ELBOW 90DEG LR ASME B16.9 BW SMLS STD, & ASTM A234 GR.WPB & 6 \\
\hline ELBO & $8^{\prime \prime}$ & $8^{\prime \prime}$ & ELBOW 90DEG LR ASME B16.9 BW SMLS STD, & ASTM A234 GR.WPB & 6 \\
\hline ELBO & $12^{\prime \prime}$ & $12^{\prime \prime}$ & ELBOW 90DEG LR ASME B16.9 BW SMLS STD, & ASTM A234 GR.WPB & 4 \\
\hline ELBO & $12^{\prime \prime}$ & $12^{\prime \prime}$ & ELBOW 45DEG ASME B16.9 BW SMLS STD, & ASTM A234 GR.WPB & 22 \\
\hline FILT & $8^{\prime \prime}$ & $1 "$ & STRAINER T-TYPE BW 150\# & $\begin{array}{l}\text { BODY-ASTM A234 GR. WPB-S } \\
\text { SCREEN-SS304 }\end{array}$ & 12 \\
\hline FLAN & $6^{\prime \prime}$ & $6^{\prime \prime}$ & $\begin{array}{l}\text { FLANGE WN ASME B16.5 \#150.RF SERRATED FINISH } \\
\text { STD, }\end{array}$ & ASTM A 105 & 7 \\
\hline FLAN & $8^{\prime \prime}$ & $8^{\prime \prime}$ & $\begin{array}{l}\text { FLANGE WN ASME B16.5 \#150.RF SERRATED FINISH } \\
\text { STD, }\end{array}$ & ASTM A105 & 6 \\
\hline FLAN & $12^{\prime \prime}$ & $12^{\prime \prime}$ & $\begin{array}{l}\text { FLANGE WN ASME B16.5 \#150.RF SERRATED FINISH } \\
\text { STD, }\end{array}$ & ASTM A 105 & 9 \\
\hline GASK & $4^{\prime \prime}$ & $4^{\prime \prime}$ & $\begin{array}{l}\text { GASKET 150\# 4.5mm SS304 + GRAFOIL FILLER C.S } \\
\text { OUTER RING ASME B16.20 }\end{array}$ & & 11 \\
\hline GASK & $6^{\prime \prime}$ & 6" & $\begin{array}{l}\text { GASKET, } 150 \#, 4.5 \mathrm{~mm} \text {, SPIRAL WOUNDSS304 + } \\
\text { GRAFOIL FILLER, C.S OUTER RING, ASME B16.20 }\end{array}$ & & 10 \\
\hline GASK & $8^{\prime \prime}$ & $8^{\prime \prime}$ & $\begin{array}{l}\text { GASKET, } 150 \#, 4.5 \mathrm{~mm} \text {, SPIRAL WOUNDSS } 304+ \\
\text { GRAFOIL FILLER, C.S OUTER RING, ASME B16.20 }\end{array}$ & & 9 \\
\hline GASK & $12^{\prime \prime}$ & $12^{\prime \prime}$ & $\begin{array}{l}\text { GASKET, } 150 \#, 4.5 \mathrm{~mm} \text {, SPIRAL WOUNDSS } 304+ \\
\text { GR AFOII. FII.I.R. C S OITTER RING ASMF. B } 16 \geqslant 0\end{array}$ & & 8 \\
\hline INST & 4" & $4 "$ & INLINE INSTRUMENT \#300, & & 45 \\
\hline INST & $6^{\prime \prime}$ & $6^{\prime \prime}$ & INLINE INSTRUMENT \#300, & & 64 \\
\hline OLET & $8^{\prime \prime}$ & 4" & WELDOLET MSS-SP97 STD, & ASTM A105 & 3 \\
\hline OLET & $6^{\prime \prime}$ & $3 / 4^{\prime \prime}$ & SOCKOLET \#3000 MSS-SP97, & ASTM A105 & 4 \\
\hline OLET & $8^{\prime \prime}$ & $3 / 4^{\prime \prime}$ & SOCKOLET \#3000 MSS-SP97, & ASTM A105 & 3 \\
\hline REDU & $6^{\prime \prime}$ & $4^{\prime \prime}$ & REDUCER CONCENTRIC ASME B16.9 BW SMLS STD, & ASTM A234 GR.WPB & 2 \\
\hline REDU & 8" & 6" & REDUCER CONCENTRIC ASME B16.9 BW SMLS STD, & ASTM A234 GR.WPB & 3 \\
\hline TEE & $4 "$ & $4 "$ & TEE ASME B16.9 BW SMLS STD, & ASTM A234 GR.WPB NACE MR-0175 & 6 \\
\hline TEE & $6^{\prime \prime}$ & $6^{\prime \prime}$ & TEE ASME B16.9 BW SMLS STD, & ASTM A234 GR.WPB & 12 \\
\hline TUBI & $12^{\prime \prime}$ & & PIPE ASME B36.10 PE SMLS STD, & ASTM A53 GR. B & 118901 \\
\hline TUBI & $20^{\prime \prime}$ & & PIPE ASME B36.10 PE SMLS STD, & ASTM A106 GR.B & 14000 \\
\hline VALV & $6^{\prime \prime}$ & $6^{\prime \prime}$ & BUTTERFLY VALVE \#150 & $\begin{array}{l}\text { BODY-ASTM A395+NBR TRIM- } \\
\text { A395+NBR WAFER GEAR API } 609\end{array}$ & 59 \\
\hline VALV & $8^{\prime \prime}$ & $8^{\prime \prime}$ & BUTTERFLY VALVE \#150 & $\begin{array}{l}\text { BODY-ASTM A395+NBR TRIM- } \\
\text { A395+NBR WAFER GEAR API } 609\end{array}$ & 87 \\
\hline
\end{tabular}

Fig. 10. Sample Bill of Quantity (BOQ) 


\section{Acknowledgment}

Abadan Oil Refinery Co supported this research. We also thank our colleagues from Kanda Idea Co who provided insight and expertise that greatly assisted the research in developing the net code. We would also like to show our gratitude to Mr. Riyahi who is Abadan Refinery Inspection Manager for sharing his pearls of wisdom with us during the course of this research.

\section{References}

AVEVA Solution Ltd, Design Reference Manual Creating the Model, User Man. (2012).

AVEVA Solution Ltd, Design Reference Manual Utilities, User Man. (2012).

AVEVA Solution Ltd, DESIGN Reference Manual General Commands, User Man., (2012).

AVEVA Solution Ltd, Administrator user guide, User Man., no. September, (2013).

AVEVA Solution Ltd, . NET Customization User Guide, User Man., (2012).

AVEVA Solution Ltd, Catalogues and Specifications User Guide, User Man., (2013).

AVEVA Solution Ltd, Isodraft User Guide, User Man., 2012.

DeVin, L. J., Ng, A. H., \& Oscarsson, J. (2004). Simulation-based decision support for manufacturing system life cycle management. Journal of Advanced Manufacturing Systems, 3(02), 115-128.

Elnaggar, B., Farshoukh, A., Almadhoun, W., \& Al-Amry, M. (2015). The road to digital asset reality. In Abu Dhabi International Petroleum Exhibition and Conference. Society of Petroleum Engineers.

Filinger, S., Talaga, J., Dylag, M., Wozny, G., \& Repke, J. (2017). Automatic equipment design for modular process units. Inżynieria i Aparatura Chemiczna.

Fillinger Sandra, Henning Bonart, Wolfgang Welscher, Erik Esche, and Jens-Uwe Repke, (2017). Improving interoperability of engineering tools -Data exchange in plant design, Chemie Ingenieur Technik, 89(11), $1454-1463$.

Freund, E., \& Pensky, D. H. (2003). Distributing 3D manufacturing simulations to realize the Digital Plant. IEEE International Conference on Robotics and Automation (Cat. No. 03CH37422), 2, 1705-1710.

Gerges, M., Austin, S., Mayouf, M., Ahiakwo, O., Jaeger, M., Saad, A., \& Gohary, T. E. (2017). An investigation into the implementation of Building Information Modeling in the Middle East. Journal of Information Technology in Construction (ITcon), 22(1), 1-15.

Goldberg, H.E. (2007). Plant and piping software design. Cadalyst, 24(3), 42-45.

Han, P. (2017). Geometry information extraction in 3D viewing model of industrial construction projects.

McPhater, N. (2010). The IT revolution. Hydrocarbon Engineering, 15(7), 40-44.

Mitkowski, P. T., \& Bal, S. K. (2015). Integration of fire and explosion index in 3D process plant design software. Chemical Engineering \& Technology, 38(7), 1212-1222.

Okey, D.,Ions, K., \& Abbas, A. (2008). Improving profitability of design engineer contractors in the process industry through design education and training. 10th International Conference on Engineering and Product Design Education.

Płocharczyk, W. (2018). Brewery installation design using AVEVA software (Doctoral dissertation, Zakład Procesów Rozdzielania).

Sandberg, T. (2017). PDMS-COMOS Data transfer development.

$\mathrm{Wu}, \mathrm{L}$. J. (2018). The development of the intelligent checking system for nuclear power plant 3D model. In 2018 International Conference on Power System Technology (POWERCON), 4668-4673.

Wen, W., Guo, X., Lu, X., Wang, Y., \& Yu, Z. (2017). Multi-scale 3D data acquisition of maize. In International Conference on Computer and Computing Technologies, 108-115.

Xiao, B., Wen, W., \& Ando Guo, X. (2011). Digital plant colony modeling based on 3D digitization. ICIC Express Letters an International Journal of Research and Surveys Part B, Applications, 2(6), 1363-1367.

Ying, Z., \& Xiao, Y. (2017). Research and application on visual aided cable design system. 25th International Conference on Nuclear Engineering, American Society of Mechanical Engineers.

Zhou, J., Liu, L., Wang, Y., Xiao, F., \& Tang, W. (2016).3-D Design review system in collaborative design of process plant. International Conference on Collaborative Computing: Networking, Applications and Work-sharing, 439-450.

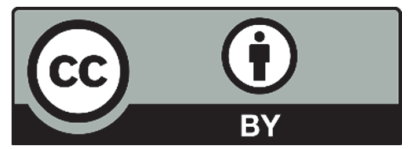

(C) 2018 by the authors; licensee Growing Science, Canada. This is an open access article distributed under the terms and conditions of the Creative Commons Attribution (CC-BY) license (http://creativecommons.org/licenses/by/4.0/). 